\title{
Raman Microscopy in Plant Science, Carotenoids Detection in Fruit Material
}

\author{
Ilinka Pećinar
}

\begin{abstract}
Non-destructive nature of Raman analysis makes it exceptionally useful for various investigations of plant materials. It afforded the analysis of carotenoids in different fruits. The introduction of the NIR-FT-Raman technique led to many applications to green plant material by eliminating the problem of sample autofluorescence.
\end{abstract}

To gain a better understanding on structure, chemical composition and properties of plant cells, tissues and organs several microscopic, chemical and physical methods have been applied during the last years (Gierlinger \& Schwanninger 2007). Raman spectroscopy with its various special techniques and methods has been applied to study plant biomass for about 30 years; such investigations have been performed at both macro- and micro-levels. Raman spectroscopy is in contrast to techniques like light microscopy, scanning electron microscopy (SEM), and transmission electron microscopy (TEM) which provide only morphological information of a material. Moreover, the non-destructive nature of Raman analysis along with none-to-minimal

How to cite this book chapter:

Pećinar, I. 2019. Raman Microscopy in Plant Science, Carotenoids Detection in Fruit Material. In: Vucelić Radović, B., Lazić, D. and Nikšić, M. (eds.) Application of Molecular Methods and Raman Microscopy/Spectroscopy in Agricultural Sciences and Food Technology, Pp. 177-186. London: Ubiquity Press. DOI: https://doi. org/10.5334/bbj.n. License: CC-BY 4.0 
requirement of sample preparation makes it exceptionally useful for various investigations. Raman spectroscopic applications on plants are very far ranging, going from investigations on structural polymers to metabolites to mineral substances (Gierlinger \& Schwanninger 2007). In the field of plant science, Raman was first applied to study tracheid cells in the xylem of woody tissues in 1980s (Atalla \& Agarwal 1986). Over the years, technological developments in the fields of filters, detectors, and lasers have made Raman instrumentation more suited to investigations of plant tissue (Agarwal 2014). Raman spectroscopy is an important method for investigating various plant tissues because it provides molecular level information on composition and structure of cellular components in situ without any staining or complicated sample preparation (i.e. cellulose and pectin: Atalla \& Agarwal 1986, Gierlinger et al. 2010, carotenoids in tomato fruit: Qin et al. 2012, Baranska et al. 2006, starch, lipid and proteins in wheat grain: Manfait et al. 2004). It is a relatively specific spectroscopic technique that measures rocking, wagging, scissoring, and stretching fundamental vibrations of functional groups containing such bonds as $\mathrm{C}=\mathrm{C}, \mathrm{C}-\mathrm{C}, \mathrm{C}-\mathrm{O}, \mathrm{C}-\mathrm{H}$ and $\mathrm{O}-\mathrm{H}$ (Marquardta \& Wold 2004). The major advantage of this technique is the capability to provide information about concentration, structure, and vibrational fingerprint of molecules within intact cells and tissues (Nikbakht et al. 2011). One of the main problems associated with the use of conventional Raman on plant materials is the very strong autofluorescence that is produced when phenolic compounds (i.e. lignin) are excited by visible light. In addition, the energies required to generate a Raman signal detectable above the autofluorescence, can cause heating and subsequent modification of the plant tissue. The introduction of the NIR-FT-Raman (1064 nm) technique led to many applications to green plant material by eliminating the problem of sample fluorescence (Agarwal 2014). For mapping and imaging of whole plant organs (seeds, fruits, leaves) the lateral resolution (about $10 \mu \mathrm{m}$ ) of the NIR-FT technique is adequate, whereas for investigations on the lower hierarchical level of cells and cell walls higher resolution gained by a visible laser based system is needed. For investigation at the cellular level and it's compartments (i.e. carotenoids inside plant cells) resonance Raman spectroscopy could give promising results (Bhosale et al. 2014). Despite the fact that Raman scattering is an extremely weak by itself, when the energy of the scattered photon matches the energy of an electronic transition of the molecules, absorption and scattering of the chromophore are strongly increased (Meinhardt-Wollweber et al. 2018). This resonance effect may enhance the Raman spectrum by several orders of magnitude, where the molecules can be detected even at lower concentrations inside the sample. In large, complex molecular structures resonance selectivity helps to identify bands originating from vibrational modes of specific parts of the molecule, such as protein-cofactor complexes. In that way the target molecules could be recognized and enhanced above the others based on their resonance behavior. 


\section{Raman microspectroscopy and carotenoids detection in fruit material}

Although carotenoids are minor components in plant material (lower than $0.1 \mathrm{mg}$ per kg; Vitek et al. 2017), due to the specifics excitation of the Raman spectra in the visible wavelength excitation (532 nm), detection of carotenoids can be achieved by resonance Raman spectroscopy (Skoczowski \& Troc, 2013; Zeise et al. 2018). Due to the high Raman activity of these compounds and the resonance effect resulting in a strong enhancement of the carotenoids bands, the resulting Raman spectroscopy has quite high potential for evaluating carotenoid biosynthesis (Vitek et al. 2017). Raman detection of carotenoid molecules allows strong and broad absorption bands for resonant excitation in the fluorescence-free wavelength at $532 \mathrm{~nm}$, appropriate for sensitive detection of the molecule's highly specific Raman response (Bhosale et al. 2014). The Raman response of carotenoids is characterized by three strong high-frequency signals originating from $\mathrm{C}=\mathrm{C}$ bond and $\mathrm{C}-\mathrm{C}$ single bond stretches of the polyene chain and from methyl bonds (Koyama 1995). In this study investigation of different carotenoids was done on several fruit types of species such as: rose, nectarine, plum, pepper, maize and tomato. The aim of the study was recognising possible differences in carotenoids in different fruit types, eg. in a case of tomato fruit was observed carotenoids changes during fruit ripening, especially in pericarp and its parts.

\section{Spectroscopic Measurements}

The Raman spectra were recorded in the range $900-2000 \mathrm{~cm}^{-1}$ with a microRaman setup (HR LabRam inverse system, Jobin Yvon Horiba). Raman scattering was excited by a frequency-doubled Nd/YAG laser at a wavelength of 532 $\mathrm{nm}$ with a laser power incident on the sample of about $2 \mathrm{~mW}$. The dispersive spectrometer has an entrance slit of $100 \mathrm{~lm}$ and a focal length of $800 \mathrm{~mm}$ and is equipped with a grating of 1200 lines $\mathrm{mm}^{-1}$. Raman scattered light was detected by a CCD camera operating at $220 \mathrm{~K}$. For the calibration procedure, titanium dioxide and 4-acetamidophenol (4AAP) were measured daily.

For the analysis of tomato carotenoids the following fruit stages were used: immmature green (20 DPA, days post antesis), mature green (39 DPA) and ripe fruit stage (52 DPA). On the fruit cross section three spots (pericarp, gel tissue and collumela) were measured for about ten times, and in total a minimum of 30 spectra were made from each fruit developmental stage. The total acquisition time per spectrum during the measurement was $1 \mathrm{~s}$, without filter corrections. These measurements were treated for baseline correction, normalization, cosmic spikes removal and intensity correction.

In Figure 1 it is clearly shown that carotenoids exhibit two strong Raman peaks in two separate spectral regions, $1100-1200$ and $1400-1600 \mathrm{~cm}^{-1}$, due 


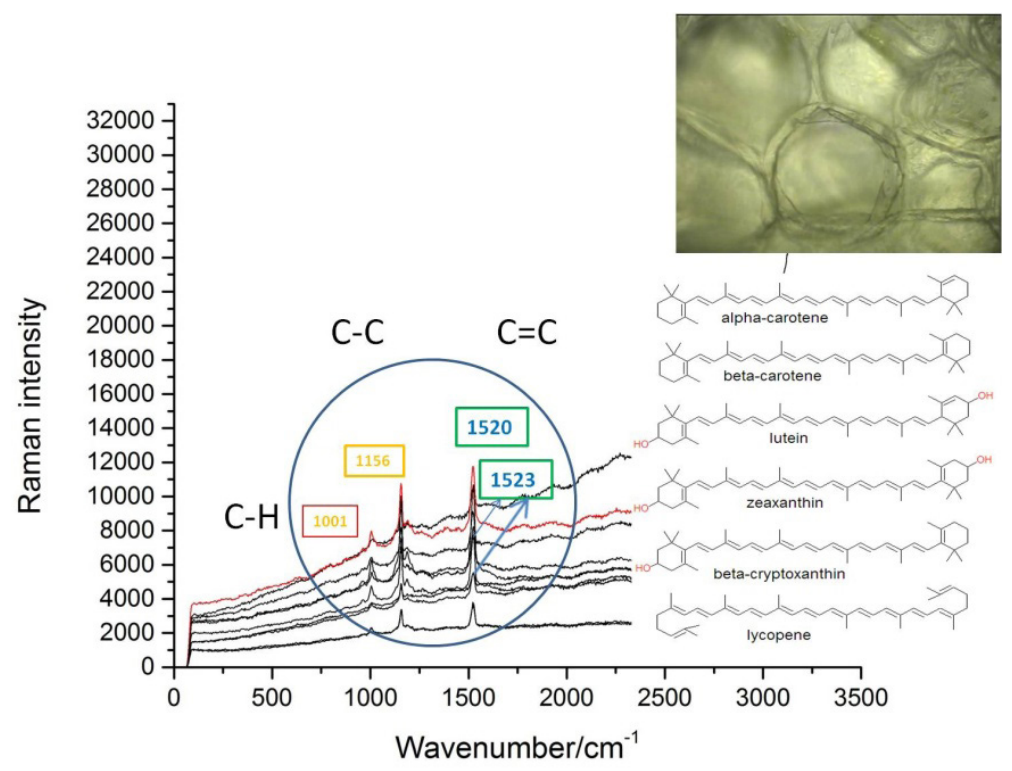

Figure 1: Raman spectrum of immature tomato fruit stage.

to the stretching vibrations of the $\mathrm{C}-\mathrm{C}$ and $\mathrm{C}=\mathrm{C}$ bonds in the polyene chain which composes the structure of carotenoids lycopene, $\beta$-carotene and a-carotene (Schulz \& Baranska 2007). Based on the intensity of the spectra in tomato immature green stage as well as at mature green fruit stage, lutein can be detected at 1520 and $1523 \mathrm{~cm}^{-1}$. It can also be noted that no carotenoids were detected in the outer pericarp, exocarp, before the first phase of ripening while in mature green fruit stage peaks that indicate the presence of $\beta$-carotene and lycopene were observed.

Lycopene occurred first in gel issue at ripe fruit stage while before that signal was not observed. The intensity of lycopene signal was growing in gel tissue and in the whole pericarp during fruit ripening. In tomato fruit at ripe stage, the bands at 1.156 and $1.510 \mathrm{~cm}^{-1}$ are related to stretching vibrations of C-C and stretching vibrations of $\mathrm{C}=\mathrm{C}$ of lycopene, respectively (Fig. 2). Moreover, the bands that appeared at $1.524 \mathrm{~cm}^{-1}, 1.157 \mathrm{~cm}^{-1}$ can be assigned to stretching $\mathrm{C}=\mathrm{C}$ and stretching $\mathrm{C}-\mathrm{C}$ of $\beta$-carotene, respectively (Schulz et al. 2006). Additionally, in-plane rocking mode of $\mathrm{CH}_{3}$ groups attached to the polyene chain and coupled with C-C bands can be observed as a peak of medium intensity in the $1.000-1.020 \mathrm{~cm}^{-1}$ region which is obvious in Figure 2.

According to Figure 1 and considering the number of conjugated bonds in carotene and lycopene, it can be concluded that the peak observed at 1.520 


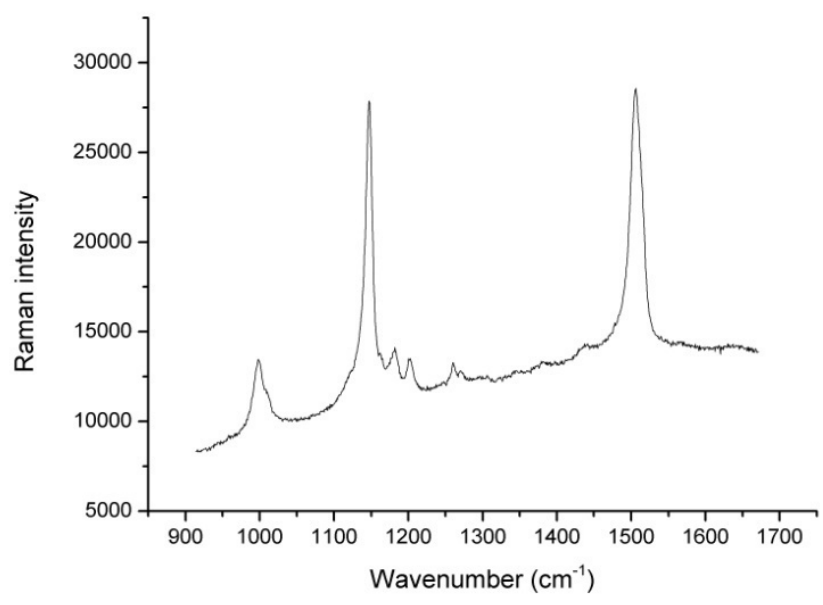

Figure 2: Raman spectrum of a red ripe tomato fruit at the region 900-1,600 $\mathrm{cm}^{-1}$, having several peaks related to stretching vibrations of $\mathrm{C}-\mathrm{C}$ and $\mathrm{C}=\mathrm{C}$ groups.

$\mathrm{cm}^{-1}$ in Figure 2 implies the predominance of carotenes rather than lycopene. However, it can be seen that the band at $1.143 \mathrm{~cm}^{-1}$ (or $1.157 \mathrm{~cm}^{-1}$ ) is asymmetric and there appear a three shoulders related to $\beta$-carotene or lycopene). The aim was to observe two separate spectral regions at better spectral resolution (grating 1200 lines $\mathrm{mm}^{-1}$ ) for better detection of carotenoids (Fig. 3). Detailed analysis of the above mentioned spectral regions was done with deconvolution of the spectra. This analysis was done by tool "peak analyzer" of Origine software using Voight function. With deconvolution of spectra some of parameters could describe different fruit carotenoids type, such as: peak area, relative intensity, position and full wide at half maximum (FWHM) of spectra. Some of parameters indicated on differentiations in tomato fruit regions related with ripening processes, especially peak relative intensity and peak area.

Similar Raman spectra for different kind of carotenoids were collected in other fruit types (Fig.4). 

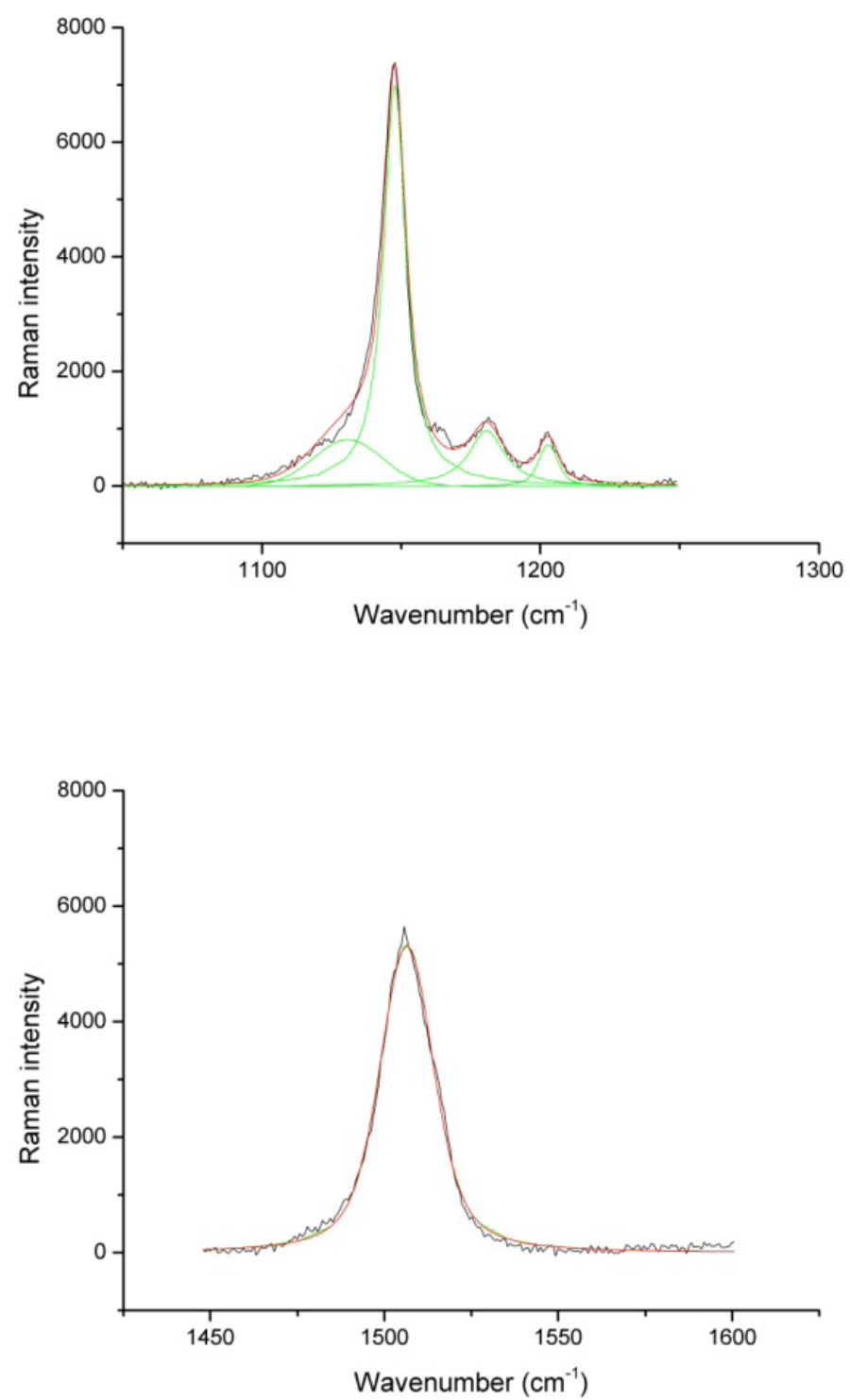

Figure 3: Deconvolution of two main carotenoids peaks in tomato fruit. 
a)

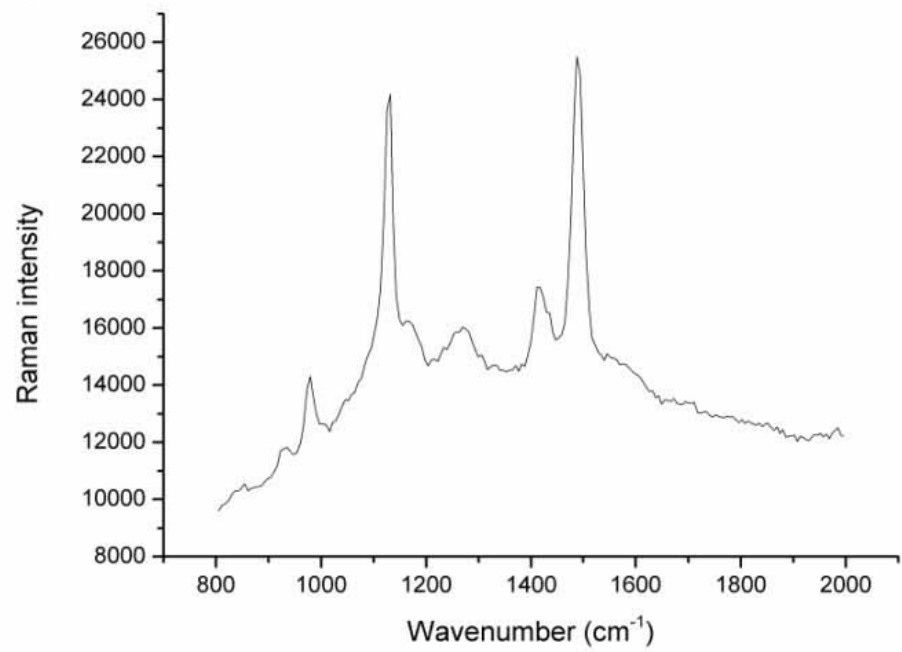

b)

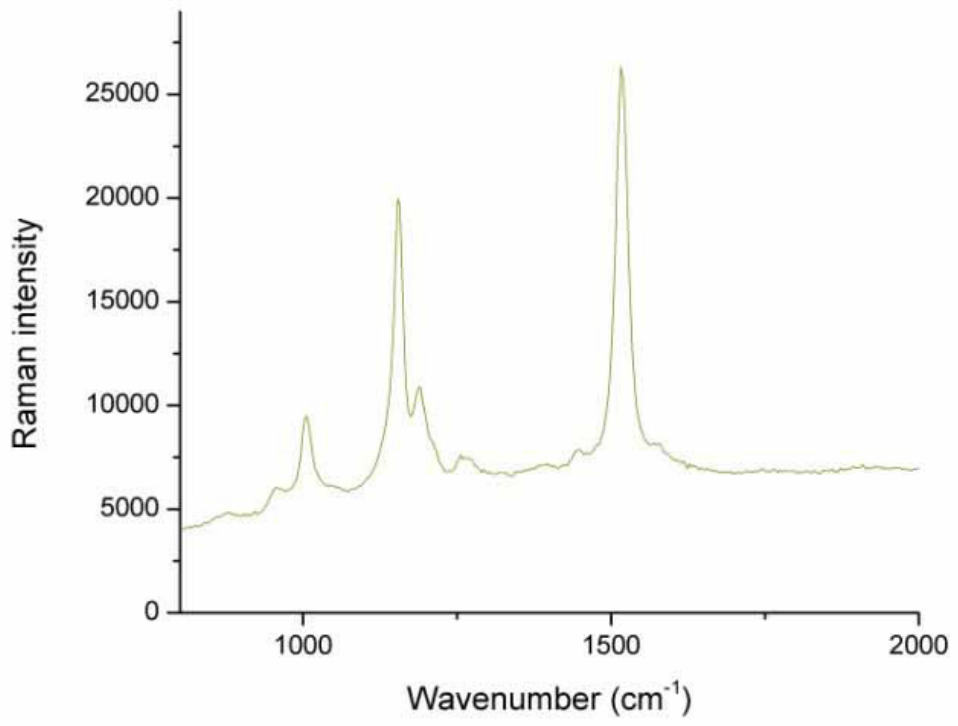

Figure 4: Raman spectra of carotenoids in other fruit types: a) rose hip, b) plum drupes, c) pepper berry, d) nectarine drupes, e) maize caryopsis. 


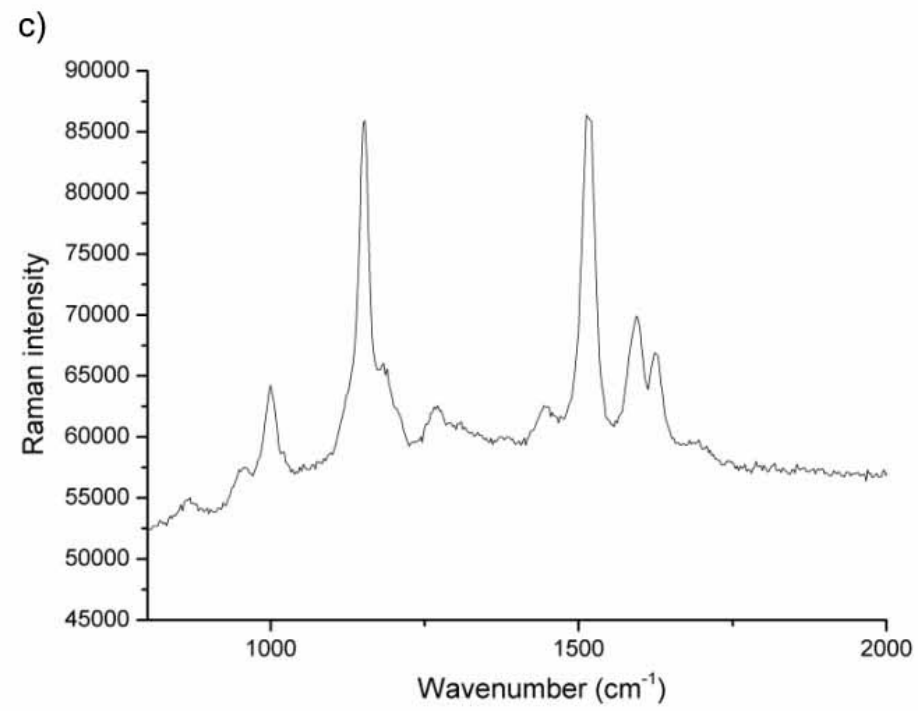

d)

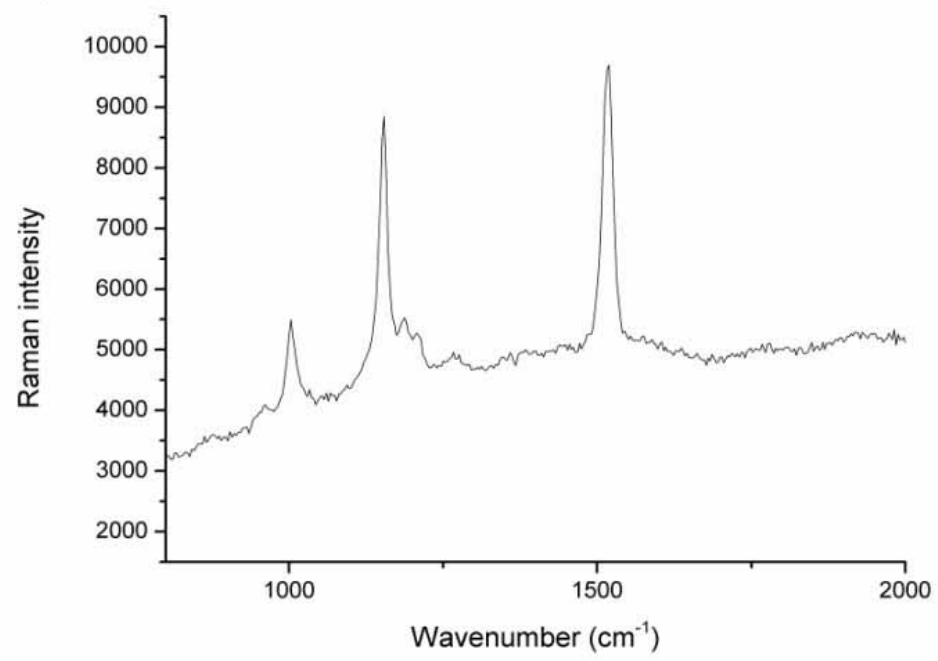

Figure 4: (continued). 


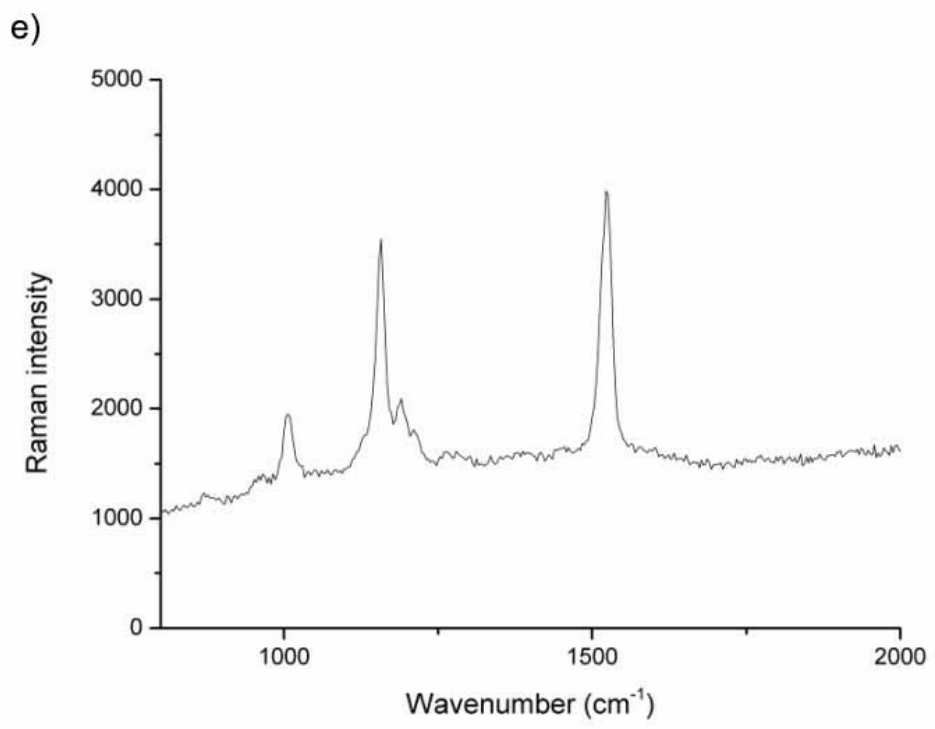

Figure 4: (continued).

\section{References}

Agarwal, U.P. (2014). 1064 nm FT- Raman spectroscopy for investigations of plant cell walls and other biomass materials. Frontiers in Plant Science. 5, 1-12. DOI: https://doi.org/10.3389/fpls.2014.00490

Atalla, R. H. \& Agarwal, U. P. (1986). Recording Raman spectra from plant cell walls. Journal of Raman Spectroscopy, 17, 229-231. DOI: https://doi. org/10.1002/jrs.1250170213

Baranska, M, Schultze, W \& Schulz, H. (2006). Determination of Lycopene and $\hat{\boldsymbol{a}}$-Carotene Content in Tomato Fruits and Related Products: Comparison of FT-Raman, ATR-IR, and NIR, Spectroscopy. Analytical Chemistry, 78, 8456-8461. DOI: https://doi.org/10.1021/ac061220j.

Bhosale, P., Ermakov, I. V., Ermakova, M. R., Gellermann, W. \& Bernstein, P. S. (2004) Resonance Raman Quantification of Nutritionally Important Carotenoids in Fruits, Vegetables, and Their Juices in Comparison to High-Pressure Liquid Chromatography Analysis, Journal of Agriculture Food Chemistry, 52, 3281-3285. DOI: https://doi.org/10.1021/jf035345q

Gierlinger, N. \& Schwanninger, M. (2007). The potential of Raman microscopy and Raman imaging in plant research. Spectroscopy 21, 69-89. http://dx.doi. org/10.1155/2007/498206.

Gierlinger, N., Luss S., König, C., Konnerth, J., Eder, M. \& Fratzl, P. (2010). Cellulose microfibril orientation of Picea abies and its variability at the micron- 
level determined by Raman imaging. Journal of Experimental Botany, 61, 587-595. DOI: https://doi.org/10.1093/jxb/erp325.

Koyama, Y. (1995). Resonance Raman spectroscopy. In Carotenoids; Britton, G., Liaaen-Jenson, S., Pfander, H., Eds.; Birkhaeuser: Basel, Switzerland, Vol. 1B, pp 135-146.

Lang, P.L., Katon, J. E., \& O’Keefe, J. F. (1986). The identification of fibers by infrared and Raman microspectroscopy. Microchemical Journal, 34, 319331. DOI: https://doi.org/10.1016/0026-265X(86)90127-X

Manfait M., Piot, O., \& Autran, J. C. (2004). Raman Mapping of Wheat Grain Kernels. Retrieved from http://www.horiba.com/fileadmin/uploads/ Scientific/Documents/Raman/Bio04.pdf

Marquardta, B. J. \& Wold, J. P. (2004). Raman Analysis of Fish: A Potential Method for Rapid Quality Screening. Lebensm.-Wiss. U.-Technology, 37, 1-8. DOI: https://doi.org/10.1016/S0023-6438(03)00114-2

Meinhardt-Wollweber, M., Suhr, C., Kniggendorf, A.-K. \& Roth, B. (2018). Absorption and resonance Raman characteristics of $\beta$-carotene in waterethanol mixtures, emulsion and hydrogel, AIP Advances 8:5 https://doi. org/10.1063/1.5025788

Nikbakht, A. M., Tavakkoli Hashjin, T., Malekfar, R. \& Gobadian, B. (2011). Nondestructive Determination of Tomato Fruit Quality Parameters Using Raman Spectroscopy, Journal of Agricultural Science and Technology, 13, 517-526.

Qin, J, Chao, K. \& Kim, MS. (2012). Nondestructive evaluation of internal maturity of tomatoes using spatially offset Raman spectroscopy. Postharvest Biology and Technology, 71, 21-31. https://doi.org/10.1016/j.postharvbio.2012.04.008

Schulz, H., Schütze, W. \& Baranska, M. (2006). Fast determination of carotenoids in tomatoes and tomato products by Raman spectroscopy. Acta Horticulture 712, 901-906. DOI: https://doi.org/10.17660/ActaHortic.2006.712.118

Schulz, H. \& Baranska, M. (2007). Identification and Quantification of Valuable Plant Substances by IR and Raman Spectroscopy. Vibrational Spectroscopy, 43, 13-25. http://dx.doi.org/10.1016/j.vibspec.2006.06.001

Skoczowski, A. \& Troc, M. (2013). Isothermal Calorimetry and Raman Spectroscopy to Study Response of Plants to Abiotic and Biotic Stresses, In Molecular Stress Physiology of Plants, Editors: Gyana Ranjan Rout, Anath Bandhu Das, Springer Dordrecht Heidelberg New York London

Vítek, P., Novotná, K., Hodaňová, P., Rapantová, B., \& Klem, K. (2017). Detection of herbicide effects on pigment composition and PSII photochemistry in Helianthus annuus by Raman spectroscopy and chlorophyll a fluorescence, Spectrochimica Acta Part A: Molecular and Biomolecular Spectroscopy, 170, 234-241. DOI: https://doi.org/10.1016/j.saa.2016.07.025

Zeise, I., Heiner, Z., Holz, S., Joester, M., Büttner, C. \& Kneipp, J. (2018). Raman Imaging of Plant Cell Walls in Sections of Cucumis sativus, Plants 7, 7, DOI: https://doi.org/10.3390/plants7010007 